\title{
Pterygium: Nonsurgical Treatment Using Topical Dipyridamole - A Case Report
}

\author{
Beth H. Carlock ${ }^{\mathrm{a}}$ Carol A. Bienstock ${ }^{\mathrm{b}}$ Moshe Rogosnitzky $^{\mathrm{b}}$ \\ ${ }^{a}$ VisionWorks, Lancaster, Pa., USA; ${ }^{b}$ MedInsight Research Institute, Telz Stone, Israel
}

\section{Key Words}

Pterygia · Pterygium · Surfer's eye · Dipyridamole

\begin{abstract}
Purpose: We report a case of a symptomatic, inflamed pterygium treated nonsurgically with topical dipyridamole and followed for 12 months. Case Report: A 35-year-old woman presented with a stage II to III, V3, C3, K2, P1 (using Johnston, Williams \& Sheppard's classification) pterygium in her right eye. She complained of a foreign body sensation, dryness, burning, and persistent uncontrolled blinking. A raised lesion was observed on the nasal conjunctiva that was $1.5 \mathrm{~mm}$ in size. It extended slightly onto the nasal cornea. There was moderate vascularity of the lesion that obscured the underlying scleral vessels. Moderate conjunctival hyperemia was detected at and medial to the pterygium. The cornea, anterior chamber, and external anatomy were otherwise unremarkable. The eye was initially treated twice daily with a topical application of dipyridamole in a normal saline solution, which was later reduced to once daily. Results: There was a marked improvement in both the pterygium and the patient's symptoms. The tissue regressed from the limbal region of the cornea, had decreased in length from 1.5 to $1.0 \mathrm{~mm}$, and decreased in height from approximately 1.0 to approximately $0.3 \mathrm{~mm}$. Conjunctival hyperemia and vascularization resolved completely, and the underlying scleral vessels could once again be visualized. At 12 months, the pterygium was graded as stage 0 to I, V0, C2, KO, PO. Conclusions: To our knowledge, this is the first case of successful management of a pterygium and associated symptoms using topical dipyridamole. Further investigation is required to clarify the potential role of dipyridamole in the treatment of pterygia and pingueculae.

(C) 2014 S. Karger AG, Basel
\end{abstract}


Carlock et al.: Pterygium: Nonsurgical Treatment Using Topical Dipyridamole - A Case Report

\section{Introduction}

Pterygia are elevated, superficial, external ocular masses that usually form over the perilimbal conjunctiva and extend onto the corneal limbus and frequently beyond. Incidence of pterygia may be as high as $30 \%$ depending on environmental factors and ultraviolet (UV) light exposure [1]. The presentation of pterygia can vary from small, atrophic quiescent lesions to large, aggressive, rapidly growing fibrovascular lesions that may distort the corneal topography, and, in advanced cases, obscure the optical center of the cornea [2,3]. Depending on the size and height of the lesion, ocular surface irritation may occur, causing patients to experience dryness and a foreign body sensation. Sometimes pterygia may become inflamed, further exacerbating these symptoms. Pterygia also create significant cosmetic concern.

Ocular surface lubrication and protective eyewear are often utilized in the early stages of pterygia. Topical indomethacin (a nonsteroidal anti-inflammatory drug) or steroids are used to decrease acute inflammation. Patients receiving topical steroids require regular monitoring of intraocular pressure due to an increased risk of glaucoma. As the pterygium grows larger, the patient often experiences more symptoms and may have decreased vision due to induced irregular astigmatism. Surgical excision is typically employed to remove the pterygium and may be accompanied by various grafting techniques [4]. However, aggressive postsurgical recurrence is a significant problem. Adjunctive therapies such as mitomycin C and irradiation have been utilized to prevent recurrence, with mixed results and potential toxicities (scleral melting and necrosis, sectorial cataract formation, and endophthalmitis) [4]. This creates a significant clinical burden, and nonsurgical treatment approaches are urgently needed.

\section{Case Report}

A 35-year-old female Caucasian patient presented with a pterygium in her right eye. She began to notice it approximately 6 weeks prior to her visit, and it rapidly became increasingly symptomatic. She complained of a foreign body sensation, burning, and dryness, accompanied by constant and uncontrolled blinking.

Three views of the patient's eye in its pre-treatment state are depicted in the figures [fig. 1, fig. 2, fig. 3 (left side)]. There was a $1.5-\mathrm{mm}$ area of raised conjunctival tissue that extended slightly onto the nasal cornea obstructing the limbus. The tissue was raised approximately $1 \mathrm{~mm}$. There was moderate vascularity of the lesion, and the underlying scleral vessels were obscured. Moderate conjunctival hyperemia was noted both at and medial to the pterygium. There appeared to be some pigmentation at the corneal leading edge of the pterygium. The ophthalmologist performing the examination noted that the lesion invaded the cornea. The cornea was otherwise clear, and the iris was unremarkable. The anterior chamber was clear and quiet. The lids and lashes were unremarkable. Utilizing Johnston, Williams \& Sheppard's comprehensive pterygium classification system [5], this was graded as a stage II to III, V3, C3, K2, P1 pterygium.

Treatment with topical steroids was recommended, but the patient declined. Instead, treatment with topically applied dipyridamole $\left(1.68 \times 10^{-4} \mathrm{M}\right.$ in normal saline solution) was initiated, starting with 1 drop twice daily to the affected area. Slight transient stinging was felt immediately upon application. The patient reported a significant reduction of dryness and burning within days of starting treatment. She continued applying the drops, and as her symptoms improved, she reduced the application to once daily. She continued applying the 
Carlock et al.: Pterygium: Nonsurgical Treatment Using Topical Dipyridamole - A Case Report

drops for 12 months with intermittent breaks of several weeks when she felt asymptomatic. The patient noticed that symptoms of dryness recurred within a few weeks, but the lesion did not increase in size. Whenever symptoms appeared, she resumed therapy. At the end of this period, the eye was reassessed. The pterygium was markedly improved. The tissue had regressed from the limbal region of the cornea, had decreased in length from 1.5 to $1.0 \mathrm{~mm}$, and decreased in height from 1.0 to approximately $0.3 \mathrm{~mm}$. The conjunctival hyperemia and vascularization had resolved entirely, and the underlying scleral vessels could now be visualized. At 12 months, the pterygium was graded as stage 0 to I, V0, C2, K0, P0 [fig. 1, fig. 2 , fig. 3 (right side)]. At the time of this report, the lesion is still present, but remains at the same very mild stage as was noted at the 12 -month evaluation.

\section{Discussion}

Despite advances in understanding, there is still no consensus on the origin and histopathogenesis of pterygia. The condition expresses features of both a degenerative and proliferative disorder. Its characterization as a degenerative disorder relates to the abnormal elastin created by chronic UV radiation exposure. The elastin is not broken down by elastase, and results in the development of a pinguecula [6]. An additional inflammatory process also generates blood vessels in the subconjunctival space contributing to the formation of fibrovascular growth that extends towards the cornea and frequently develops into a pterygium. As reviewed by Chui et al. [7] in 2011, this process is accompanied by Bowman's layer dissolution, epithelial-mesenchymal transition, and an activated fibroblastic stroma with inflammation, neovascularization, and matrix remodeling. This is mediated through the concerted actions of cytokines, growth factors, and matrix metalloproteinases [7].

The characterization of a pterygium as a proliferative disorder relates to the abnormal, uncontrolled proliferation of altered basal epithelial stem cells in the limbal bed that encroach into the conjunctival tissue. Pterygia also mimic certain tumor behaviors: they attack healthy tissue in the conjunctiva via fibrovascular growth, they have a high recurrence rate following surgical resection, and they can occur concurrently with secondary premalignant lesions [7]. Due to the possible evolution into precursors of malignant ocular melanoma and squamous cell carcinoma, early and complete treatment is ideal to prevent unwanted progression to more serious disease expression [7].

In addition to the abundance of evidence that chronic UV radiation is a causative factor in the development and progression of pterygia, viral activity has also been implicated [8]. The same types of human papilloma virus (HPV) have been reported in papillomas and pterygia, and it has been theorized that the recurrence of pterygia following excision may be a result of persistent conjunctival HPV [8].

Dipyridamole (Persantin ${ }^{\circledR}$, Cardoxin $^{\circledR}$ ) was originally introduced in 1959 as an antianginal medication and was subsequently found to inhibit platelet aggregation. It has a long history of safe usage. Long-term high-dose studies in mice have demonstrated that it is noncarcinogenic and nonmutagenic [9]. The typical oral daily dose in humans ranges between 225 and $400 \mathrm{mg}$. The daily dose delivered to the eye surface in our patient was in the order of $1 / 25,000$ th to $1 / 50,000$ th of the typical daily oral dose. In comparison, the antibiotic moxifloxacin HCL ocular solution (Vigamox ${ }^{\circledR}$ ) is administered at $1 / 700$ th of the typical daily oral dose of moxifloxacin and the immunosuppressant cyclosporine (Restasis ${ }^{\circledR}$ ) is administered at $1 / 400$ th of the typical daily oral dose of cyclosporine. 
Carlock et al.: Pterygium: Nonsurgical Treatment Using Topical Dipyridamole - A Case Report

Dipyridamole has also been shown to possess effects that are potentially quite relevant to pterygia. One of those effects is anti-inflammatory activity [10]. A recent study attributed its anti-inflammatory effects to the suppression of TNF- $\alpha$ and PMA-mediated MMP-9 expression and interference with NF- $\beta$ signaling and p38 MAPK activation [10]. Furthermore, it possesses antineoplastic properties [11], and additionally has been found to possess antiviral properties [12] that could address the theorized association between conjunctival $\mathrm{HPV}$ and pterygia.

Animal experimentation using intravitreal administration of dipyridamole has shown that it regulates ocular blood flow [13]. In human research, a study of patients with anterior ischemic optic neuropathy, vasospastic syndrome, glaucoma or central retinal vein occlusion using oral dipyridamole (75 mg TID) demonstrated significantly increased blood flow velocities for all measured vessels [14]. Dipyridamole has also been studied in animals for reduction of intraocular pressure. Systemic administration of dipyridamole in rabbits was found to counteract elevations of intraocular pressure and anterior chamber aqueous humor protein produced by topical application of prostaglandin E2 [15].

Dipyridamole's anti-inflammatory, antiviral, antiproliferative, and (at low doses) antioxidant properties make it a novel prospective candidate to address the apparent multifaceted etiology of pterygia.

\section{Conclusion}

This report represents the first case of successful management of an inflamed pterygium and its partial regression with nonsurgical treatment utilizing topical dipyridamole. The use of topical dipyridamole needs to be investigated further to clarify its potential role in the treatment of pterygia (and pingueculae, due to histological similarity), especially when associated with complications of inflammation and dry eye.

\section{Disclosure Statement}

Moshe Rogosnitzky has pending patents for dipyridamole in the treatment of dry eye, corneal ulcers, pterygia, and pingueculae.

\section{References}

1 Bruce AS, Loughnan MS: Anterior Eye Disease and Therapeutics A-Z. Chatswood, Elsevier Australia, 2011.

-2 Coroneo MT, Di Girolamo N, Wakefield D: The pathogenesis of pterygia. Curr Opin Ophthalmol 1999;10:282-288.

-3 Elliott R: The aetiology of pterygium. Trans Ophthalmol Soc N Z 1961;13(suppl):22-41.

-4 Ang LPK, Chua JLL, Tan DTH: Current concepts and techniques in pterygium treatment. Curr Opin Ophthalmol 2007;18:308-313.

5 Johnston SC, Williams PB, Sheppard JD Jr: A comprehensive system for pterygium classification. ARVO Meet Abstr 2004;45:2940.

-6 Austin P, Jakobiec FA, Iwamoto T: Elastodysplasia and elastodystrophy as the pathologic bases of ocular pterygia and pinguecula. Ophthalmology 1983;90:96-109.

7 Chui J, Coroneo MT, Tat LT, Crouch R, Wakefield D, Di Girolamo N: Ophthalmic pterygium: a stem cell disorder with premalignant features. Am J Pathol 2011;178:817-827.

8 Chalkia AK, Spandidos DA, Detorakis ET: Viral involvement in the pathogenesis and clinical features of ophthalmic pterygium (review). Int J Mol Med 2013;32:539-543. 


\begin{tabular}{l|l}
\hline Case Rep Ophthalmol 2014;5:98-103 \\
\hline DOI: 10.1159/000362113 & $\begin{array}{l}\text { @ 2014 S. Karger AG, Basel } \\
\text { www.karger.com/cop }\end{array}$ \\
\hline
\end{tabular}

Carlock et al.: Pterygium: Nonsurgical Treatment Using Topical Dipyridamole - A Case Report

$9 \quad$ FDA Aggrenox Labeling

http://www.accessdata.fda.gov/drugsatfda_docs/nda/99/20884_aggrenox_prntlbl.pdf (accessed November 25, 2013).

10 Massaro M, Scoditti E, Carluccio MA, Pellegrino M, Calabriso N, Storelli C, Martines G, DeCaterina R: Dipyridamole decreases inflammatory metalloproteinase- 9 expression and release by human monocytes. Thromb Haemost 2009;102:538-543.

11 Chen WH, Yin HL, Chang YY, Lan MY, Hsu HY, Liu JS: Antiplatelet drugs induce apoptosis in cultured cancer cells. Kaohsiung J Med Sci 1997;13:589-597.

-12 Surkina ID: Antiviral and regulatory interferon-inducing effects of dipyridamole (in Russian). Ter Arkh 2000;72:61-64.

13 Braunagel SC, Xiao JG, Chiou GC: The potential role of adenosine in regulating blood flow in the eye. J Ocul Pharmacol Ther 1988;4:61-73.

14 Kaiser HJ, Stümpfig D, Flammer J: Short-term effect of dipyridamole on blood flow velocities in the extraocular vessels. Int Ophthalmol 1995;19:355-358.

15 Podos SM: Effect of dipyridamole on prostaglandin-induced ocular hypertension in rabbits. Invest Ophthalmol Vis Sci 1979;18:646-648.

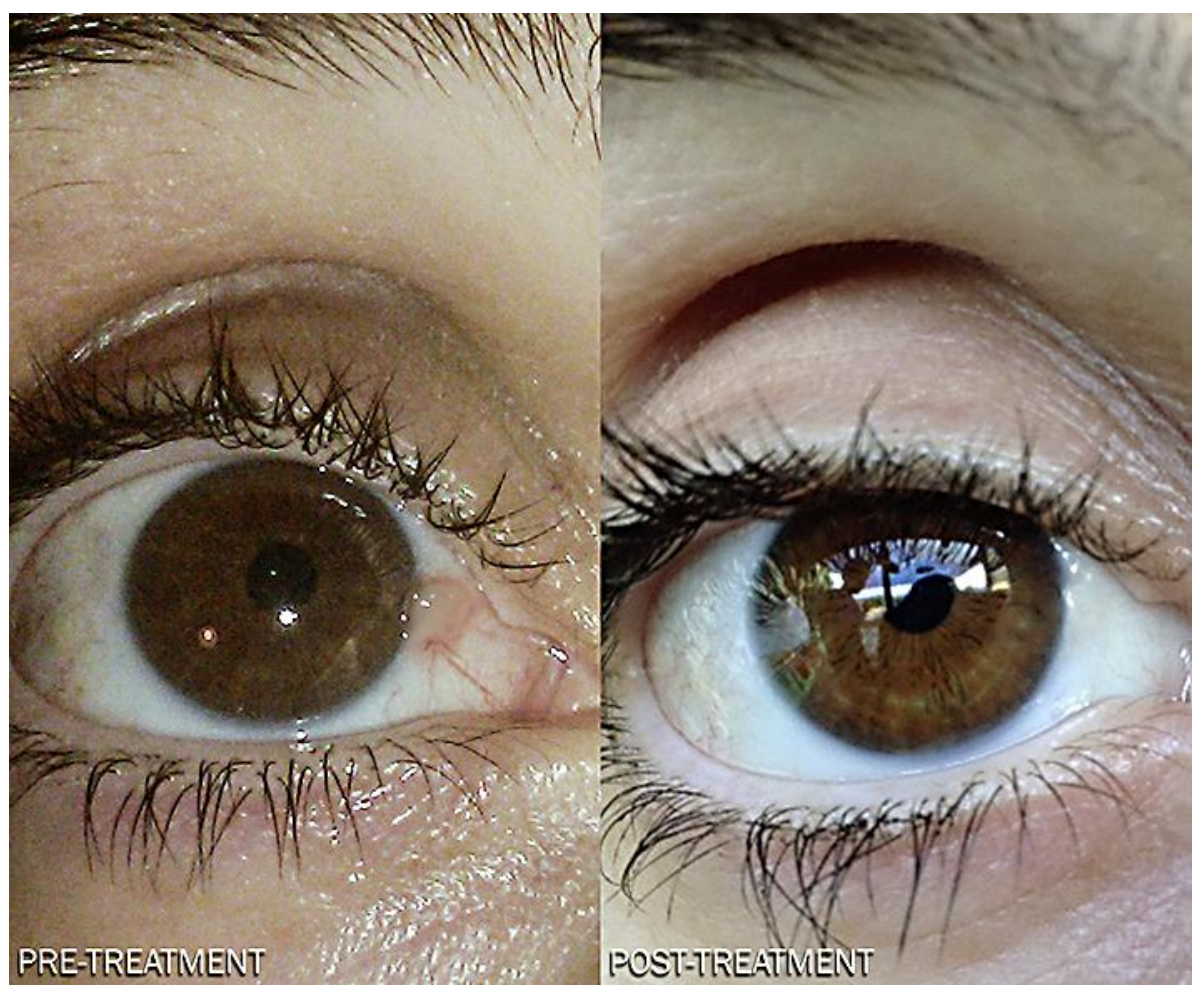

Fig. 1. View 1 of the patient's eye in pre-treatment and post-treatment states. 
Case Reports in

Ophthalmology

\begin{tabular}{l|l}
\hline Case Rep Ophthalmol 2014;5:98-103 & \\
\hline DOI: 10.1159/000362113 & $\begin{array}{l}\text { ○ 2014 S. Karger AG, Basel } \\
\text { www.karger.com/cop }\end{array}$ \\
\hline
\end{tabular}

Carlock et al.: Pterygium: Nonsurgical Treatment Using Topical Dipyridamole - A Case Report

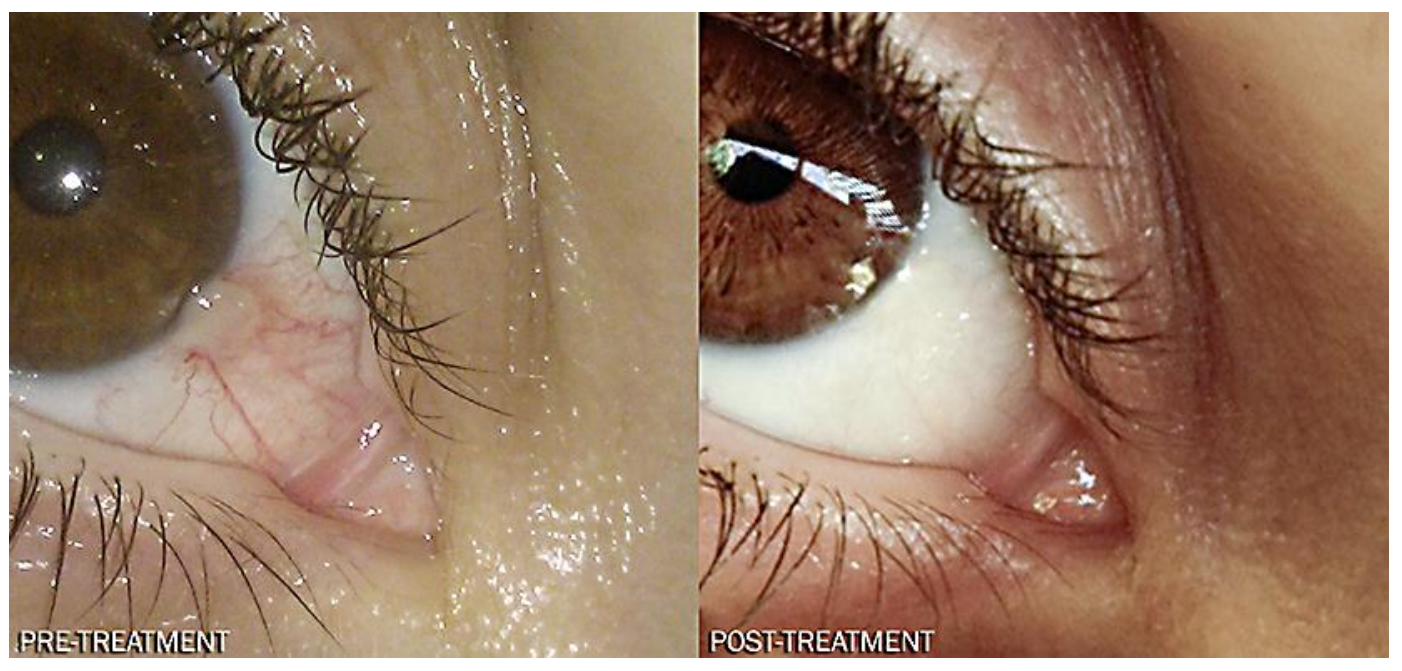

Fig. 2. View 2 of the patient's eye in pre-treatment and post-treatment states.

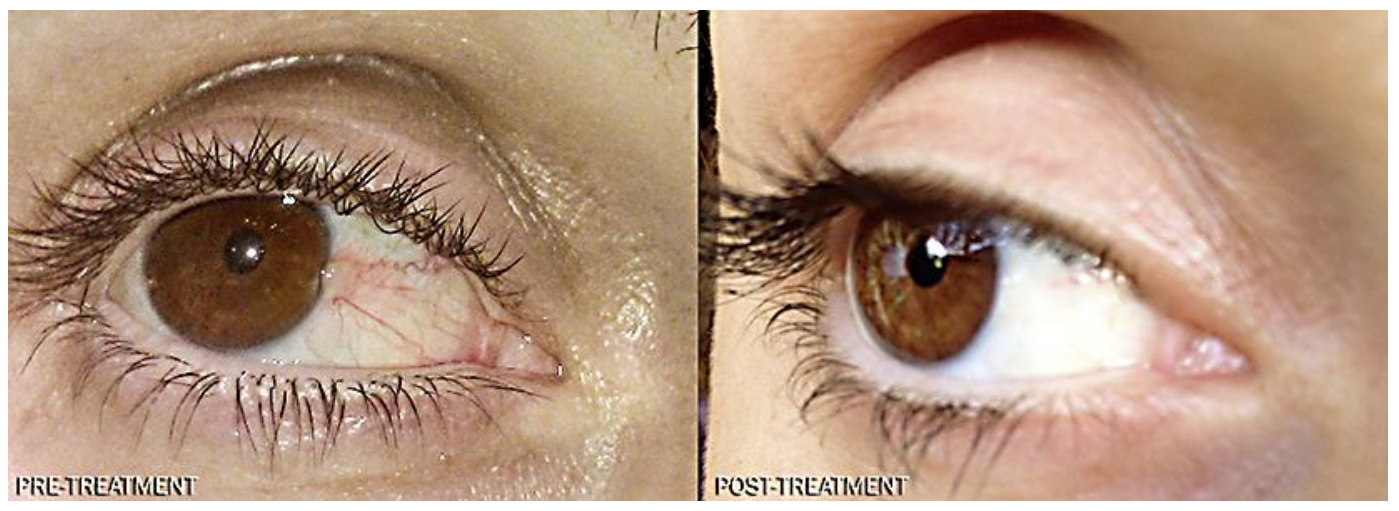

Fig. 3. View 3 of the patient's eye in pre-treatment and post-treatment states. 